\title{
Amendment of the Genus Saccharothrix Labeda et al. 1984 and Descriptions of Saccharothrix espanaensis sp. nov., Saccharothrix cryophilis sp. nov., and Saccharothrix mutabilis comb. nov.
}

\author{
D. P. LABEDA ${ }^{1 *}$ AND M. P. LECHEVALIER ${ }^{2}$
}

Northern Regional Research Center, Agricultural Research Service, United States Department of Agriculture, Peoria, Illinois 61604, ${ }^{1}$ and Waksman Institute of Microbiology, Rutgers, The State University, Piscataway, New Jersey 08855-0759

\begin{abstract}
The description of the genus Saccharothrix is amended to include strains having either a type PII (phosphatidylethanolamine) or a type PIV (phosphatidylethanolamine and glucosamine-containing phospholipids) phospholipid pattern. A new antibiotic-producing species, Saccharothrix espanaensis (type strain, NRRL 15764), is described. Nocardiopsis mutabilis Shearer et al. 1983 is transferred to the amended genus as Saccharothrix mutabilis comb. nov. "Nocardiopsis mutabilis subsp. cryophilis" Takahashi et al. 1986 is described as a new species, Saccharothrix cryophilis, based on its physiological properties and lack of high levels of deoxyribonucleic acid relatedness to the previously described Saccharothrix species.
\end{abstract}

The genus Saccharothrix was described to contain strains that exhibit fragmenting substrate and aerial mycelia and have type III cell walls (meso isomer of diaminopimelic acid) and rhamnose and galactose as whole-cell diagnostic sugars. The original description limited the genus to microorganisms with a type PII phospholipid pattern sensu Lechevalier et al. (phosphatidylethanolamine as a diagnostic phospholipid).

During the course of screening actinomycetes from soil for the production of new secondary metabolites, a novel strain isolated from a soil sample from Puerto Llano, Spain, was found to produce the weakly basic polysaccharide antibiotic LL-C19004 (J. P. Kirby, W. M. Maiese, R. T. Testa, and D. P. Labeda, U.S. patent 4,699,790, October 1987). The producing strain was found to have a cell wall composition and whole-cell sugar pattern typical of the genus Saccharothrix. The phospholipid composition of this strain differed from that observed in previously described strains of Saccharothrix species, Saccharothrix australiensis NRRL 11239 (8), Saccharothrix aerocolonigenes NRRL B-3298 (5), Saccharothrix texasensis NRRL B-16134 (7), and Saccharothrix waywayandensis NRRL B-16159 (7), in that it had both glucosamine-containing phospholipids and phosphatidylethanolamine (type PIV phospholipid pattern versus type PII). Nocardiopsis mutabilis (15) and "Nocardiopsis mutabilis subsp. cryophilis" (17) also have been observed to have a type PIV phospholipid pattern and are otherwise morphologically and chemotaxonomically (containing meso-diaminopimelic acid and galactose and rhamnose) typical of the genus Saccharothrix rather than of the genus Nocardiopsis, the members of which lack rhamnose as a diagnostic wholecell sugar and have a type PIII phospholipid pattern. The erection of a new genus to contain strains having glucosamine-containing phospholipids in their phospholipid pattern is not warranted at this time because of the similarity of all of these strains based on morphological criteria and all other chemotaxonomic criteria. Therefore, we propose to amend the description of the genus Saccharothrix to include strains having either a type PII or a type PIV phospholipid pattern. A new species, Saccharothrix espanaensis, is proposed for the strain which produces LL-C19004, with strain NRRL 15764 as the type strain. The proposed transfer of $N$.

\footnotetext{
* Corresponding author.
}

mutabilis to the genus Saccharothrix as Saccharothrix mutabilis has also been suggested by Grund and Kroppenstedt (E. Grund and R. Kroppenstedt, Syst. Appl. Bacteriol., in press), but this could not have been validly accomplished unless the genus description was amended to permit the inclusion of strains having a type PIV phospholipid pattern. The proposed amendment of the genus permits the valid transfer of this species as Saccharothrix mutabilis comb. nov. An evaluation of the physiological properties of " $N$. mutabilis subsp. cryophilis" and its lack of "species level" $(>70 \%)$ deoxyribonucleic acid (DNA) relatedness to $N$. mutabilis and other previously described Saccharothrix species indicate that this organism should be transferred to the genus Saccharothrix as a new species, for which the name Saccharothrix cryophilis is proposed.

\section{MATERIALS AND METHODS}

Strain maintenance. The strains evaluated in this study (Table 1) were maintained on agar slants of American Type Culture Collection (ATCC) medium 172 (1) and were stored at $4^{\circ} \mathrm{C}$ until they were needed. Inoculum for physiological tests and biomass for extraction of menaquinones and phospholipids were grown in ATCC medium 172 broth. Biomass for extraction of DNA was grown in ATCC medium 172 broth without calcium carbonate.

TABLE 1. Strains of Saccharothrix species compared in this study

\begin{tabular}{|c|c|c|}
\hline Strain & Species & $\begin{array}{c}\text { Guanine-plus- } \\
\text { cytosine } \\
\text { content of } \\
\text { DNA (mol\%) }\end{array}$ \\
\hline NRRL $11239^{\mathrm{T} a}$ & S. australiensis & 75.9 \\
\hline NRRL B-3298 ${ }^{\mathrm{T}}$ & S. aerocolonigenes & 70.0 \\
\hline NRRL B-16134 ${ }^{T}$ & S. texasensis & 74.9 \\
\hline NRRL B-16159 & S. waywayandensis & 71.2 \\
\hline NRRL $15764^{\mathrm{T}}$ & S. espanaensis & 72.2 \\
\hline NRRL B-16077 & $\begin{array}{l}\text { S. mutabilis (synonym, N. muta- } \\
\text { bilis) }\end{array}$ & 73.1 \\
\hline NRRL B-16238 ${ }^{\mathrm{T}}$ & $\begin{array}{l}\text { S. cryophilis (synonym, "N. mu- } \\
\text { tabilis subsp. cryophilis") }\end{array}$ & 71.4 \\
\hline
\end{tabular}

${ }^{a} \mathrm{~T}=$ type strain. 
TABLE 2. Differential physiological properties of Saccharothrix species

\begin{tabular}{|c|c|c|c|c|c|c|c|}
\hline Characteristic & S. australiensis & S. aerocolonigenes & S. texasensis & S. waywayandensis & S. espanaensis & S. mutabilis & S. cryophilis \\
\hline \multicolumn{8}{|l|}{ Decomposition of: } \\
\hline Adenine & - & - & + & - & - & - & - \\
\hline Casein & + & + & + & + & + & + & - \\
\hline Hippurate & - & - & + & + & + & + & - \\
\hline Hypoxanthine & _- & + & + & + & + & + & - \\
\hline Potato starch & - & + & + & + & - & + & - \\
\hline Tyrosine & + & + & + & + & - & + & + \\
\hline Urea & - & $\mathrm{v}^{a}$ & $\mathrm{v}$ & + & - & - & + \\
\hline \multicolumn{8}{|l|}{ Acid produced from: } \\
\hline Adonitol & - & - & - & + & - & - & - \\
\hline L-Arabinose & - & + & + & + & - & + & - \\
\hline Cellobiose & + & + & + & + & + & + & - \\
\hline Dextrin & + & + & + & + & - & + & - \\
\hline meso-erythritol & + & - & - & + & - & - & - \\
\hline Glycerol & + & + & + & + & + & + & $\mathrm{w}^{b}$ \\
\hline myo-inositol & - & + & + & + & - & + & + \\
\hline Lactose & _- & + & + & + & - & + & + \\
\hline Melibiose & - & + & + & + & - & + & - \\
\hline Raffinose & - & + & - & + & - & + & $\mathrm{w}$ \\
\hline L-Rhamnose & - & + & + & + & - & - & - \\
\hline Salicin & - & + & + & + & - & + & - \\
\hline D-Sorbitol & + & - & - & - & - & - & - \\
\hline Sucrose & - & + & + & + & + & + & - \\
\hline D-Xylose & - & + & + & + & $\mathrm{v}$ & + & - \\
\hline$\alpha$-Methyl-D-glucoside & - & $\mathrm{v}$ & + & - & - & + & - \\
\hline$\beta$-Methyl-D-xyloside & - & $\mathbf{v}$ & $\mathrm{v}$ & - & - & $\mathrm{ND}^{c}$ & - \\
\hline \multicolumn{8}{|l|}{ Utilization of: } \\
\hline Citrate & - & + & - & + & $\mathrm{v}$ & + & - \\
\hline Oxalate & - & + & - & + & - & - & + \\
\hline DL-Tartrate & - & + & - & - & - & - & - \\
\hline \multicolumn{8}{|l|}{ Production of: } \\
\hline Nitrate reductase & + & + & + & - & w & + & + \\
\hline Phosphatase & - & + & + & + & + & + & + \\
\hline \multicolumn{8}{|l|}{ Growth in the presence of: } \\
\hline $4 \% \mathrm{NaCl}$ & + & + & - & + & + & - & + \\
\hline $5 \% \mathrm{NaCl}$ & - & $\mathrm{w}$ & - & + & - & - & - \\
\hline \multicolumn{8}{|l|}{ Growth at: } \\
\hline $37^{\circ} \mathrm{C}$ & + & + & + & + & + & + & - \\
\hline $42^{\circ} \mathrm{C}$ & + & $\mathrm{v}$ & + & - & + & + & - \\
\hline $45^{\circ} \mathrm{C}$ & + & - & - & - & - & + & - \\
\hline
\end{tabular}

${ }^{a} \mathrm{v}$, Variable response.

${ }^{b} \mathrm{w}$, Weak response.

c ND, Not determined.

Morphological observations. Gross morphological observations were made by using cultures grown for 14 days at $28^{\circ} \mathrm{C}$ on the standard media suggested by the International Streptomyces Project (16) and ATCC medium 172. Micromorphology and sporulation on the same media were observed by light microscopy and scanning electron microscopy.

Physiological tests. Physiological tests, including production of acid from carbohydrates, utilization of organic acids, and hydrolysis and decomposition of adenine, guanine, hypoxanthine, tyrosine, xanthine, casein, esculin, urea, and hippurate, were evaluated by using the media of Gordon et al. (2). Allantoin hydrolysis was evaluated in the basal medium suggested by Gordon et al. for esculin hydrolysis. Phosphatase activity was evaluated by using the method of Kurup and Schmitt (4). The temperature range for growth was determined on slants of ATCC medium 172 agar, and tolerance to $\mathrm{NaCl}$ was measured by supplementing ATCC medium 172 agar with various concentrations of $\mathrm{NaCl}$.

Chemotaxonomy. Chemotaxonomic properties of strains (isomer of diaminopimelic acid, whole-cell sugar content, phospholipid pattern, and menaquinone content) were determined by previously described methods $(6,9,10)$.
Purification of DNA and determination of relatedness. DNA was extracted from cells by using the method of Marmur (11) and was further purified by chromatography on hydroxylapatite columns. The guanine-plus-cytosine content of the DNA was calculated from the thermal denaturation midpoint $\left(T_{m}\right)$, which was determined by the method of Marmur and Doty (12). The percentage of DNA relatedness between strains was calculated from $\mathrm{C}_{0} \mathrm{t}_{0.5}$ determinations in $5 \times \mathrm{SSC}$ (1× SSC is $0.15 \mathrm{M} \mathrm{NaCl}$ plus $0.015 \mathrm{M}$ sodium citrate) supplemented with $20 \%$ dimethyl sulfoxide at $66^{\circ} \mathrm{C}\left(T_{m}-\right.$ $25^{\circ} \mathrm{C}$ ) by using the method of Seidler and Mandel (14) and Seidler et al. (13) as described by Kurtzman et al. (3).

\section{RESULTS}

Morphologically, the strains of Saccharothrix species are very similar. The substrate mycelia tend to be plicate and yellow to brownish yellow. Sparse white to yellowish white aerial mycelia are provided by most strains on some media, generally inorganic salts-starch agar (International Streptomyces Project medium 4) or Czapek agar. Substrate and aerial mycelia typically fragment. 
TABLE 3. Levels of DNA relatedness between Saccharothrix species

\begin{tabular}{|c|c|c|c|c|c|c|c|}
\hline \multirow[b]{2}{*}{ Strain } & \multicolumn{7}{|c|}{ \% DNA relatedness to strain: } \\
\hline & $\begin{array}{l}\text { NRRL } \\
11239^{\text {Ta }}\end{array}$ & $\begin{array}{l}\text { NRRL } \\
\text { B-3298 }\end{array}$ & $\begin{array}{c}\text { NRRL } \\
\text { B-16134 }\end{array}$ & $\begin{array}{c}\text { NRRL } \\
\text { B-16159 }\end{array}$ & $\begin{array}{c}\text { NRRL } \\
\text { B-16158 }\end{array}$ & $\begin{array}{l}\text { NRRL } \\
15764^{\mathrm{T}}\end{array}$ & $\begin{array}{c}\text { NRRL } \\
\text { B-16077 }\end{array}$ \\
\hline S. aerocolonigenes NRRL B- $3298^{\mathrm{T}}$ & 10 & & & & & & \\
\hline S. texasensis NRRL B-16134 ${ }^{\mathrm{T}}$ & 21 & 0 & & & & & \\
\hline S. waywayandensis NRRL B-16159 & 3 & 44 & 7 & & & & \\
\hline S. waywayandensis NRRL B-16158 & 11 & 34 & 5 & 95 & & & \\
\hline S. espanaensis NRRL $15764^{\mathrm{T}}$ & 25 & 2 & 17 & 12 & 0 & & \\
\hline S. mutabilis NRRL B-16077 ${ }^{\mathrm{T}}$ & 18 & 17 & 12 & 4 & 0 & 0 & \\
\hline S. cryophilis NRRL B-16238 & 6 & 11 & 4 & 4 & 2 & 9 & 9 \\
\hline
\end{tabular}

${ }^{a}$ Strain NRRL $11239^{\mathrm{T}}$ is a strain of $S$. australiensis.

The cell walls contain the meso isomer of diaminopimelic acid, and rhamnose and galactose are the characteristic whole-cell sugars. The predominant menaquinone is MK$9\left(\mathrm{H}_{4}\right)$. Phosphatidylethanolamine is the diagnostic nitrogencontaining phospholipid, which is typical of the type PII phospholipid pattern. S. espanaensis, N. mutabilis, and " $N$. mutabilis subsp. cryophilis" also include glucosamine-containing phospholipids, which are typical of the type PIV phospholipid pattern.

The differential physiological properties of Saccharothrix species are summarized in Table 2. DNA relatedness data are shown in Table 3. Strains that exhibit more than $70 \%$ DNA relatedness are defined as belonging to the same species, while values below $20 \%$ have been observed between unrelated species within other actinomycete genera (Labeda, unpublished data). S. waywayandensis and $S$. aerocolonigenes may represent sibling species based on their levels of DNA relatedness, while $S$. espanaensis exhibits slightly more than a background level of relatedness to S. australiensis.

\section{DISCUSSION}

Strains characterized as Saccharothrix species share key morphological and chemotaxonomic characteristics (i.e., fragmentation of substrate and aerial mycelia, type III cell walls [meso-diaminopimelic acid], and rhamnose and galactose as diagnostic whole-cell sugars). All of the strains of Saccharothrix species investigated to date contain phosphatidylethanolamine as a diagnostic phospholipid and menaquinone MK- $9\left(\mathrm{H}_{4}\right)$ as the predominant menaquinone. Based on the overall similarities of these characteristics for all strains, it appears that the presence or absence of glucosaminecontaining phospholipids (type PII pattern versus type PIV pattern) may not be taxonomically significant in this genus. Therefore, we propose that the description of the genus Saccharothrix be amended to include strains having either a type PII or type PIV phospholipid pattern. An amended formal description of the genus Saccharothrix is given below.

Amended description of the genus Saccharothrix. Saccharothrix (Sac' char. o. thrix. Gr. neut. n. sacchar, sugar; Gr. fem. n. thrix, hair; Saccharothrix, sugar-containing hair). Branching vegetative mycelia (diameter, approximately 0.5 $\mu \mathrm{m})$ and, on some media, aerial mycelia are produced. Both vegetative and aerial hyphae fragment into ovoid elements. Gram positive. Lysozyme resistant. Catalase positive and aerobic. The cell wall is type III (meso-diaminopimelic acid, L-alanine, D-alanine, D-glutamic acid, glucosamine, muramic acid), and the whole-cell sugar pattern consists of major amounts of galactose (in the absence of arabinose) and rhamnose. The phospholipid pattern consists of phosphatidylethanolamine as the diagnostic phospholipid with or without glucosamine-containing phospholipids (type PII or PIV). Nocardomycolic acids are absent. The guanine-pluscytosine content of the DNA is 70 to $76 \mathrm{~mol} \%$. The type species is $S$. australiensis.

Upon amendment of the genus description, $S$. espanaensis and $N$. mutabilis can be placed in this genus based on morphological and chemotaxonomic criteria. The proposed new species Saccharothrix espanaensis and Saccharothrix mutabilis, resulting from the transfer of Nocardiopsis mutabilis Shearer et al. 1983 (15) to the amended genus, are formally described below.

Saccharothrix espanaensis sp. nov. Saccharothrix espanaensis (es. pan. a. en' sis. L. adj. espanaensis, referring to the source of the soil sample, Puerto Llano, Spain, from which the organism was first isolated). Substrate mycelium grayish yellow to yellowish brown. Sparse white aerial mycelium is produced on some media, particularly on inorganic salts-starch agar and glycerol-asparagine agar. A yellow soluble pigment is produced on glycerol-asparagine agar and inorganic salts-starch agar. Brown to reddish brown soluble pigments are produced on yeast extract-malt extract agar and on ATCC medium 172. Casein, esculin, hippurate, and hypoxanthine are hydrolyzed or decomposed; adenine, allantoin, cellulose, gelatin, guanine, starch, tyrosine, urea, and xanthine are not hydrolyzed or decomposed. Nitrate is weakly reduced to nitrite. Phosphatase is produced. Acetate, DL-lactate, DL-malate, and succinate are assimilated; benzoate, mucate, oxalate, and DL-tartrate are not assimilated; and assimilation of citrate and propionate is variable. Acid is produced from cellobiose, D-fructose, D-galactose, D-glucose, glycerol, D-mannose, sucrose, and trehalose; no acid is produced from adonitol, L-arabinose, dextrin, dulcitol, meso-erythritol, myo-inositol, lactose, D-mannitol, melibiose, $\alpha$-methyl-D-glucoside, $\beta$-methyl-D-xyloside, raffinose, L-rhamnose, salicin, and D-sorbitol; and acid production from maltose and D-xylose is variable. Growth occurs in the presence of $4 \% \mathrm{NaCl}$ but not in the presence of $5 \% \mathrm{NaCl}$. The temperature range for growth is 15 to $42^{\circ} \mathrm{C}$. The guanineplus-cytosine content of the DNA is $72.2 \mathrm{~mol} \%$ (thermal denaturation midpoint method). Produces the antibiotic LLC19004. Isolated from soil. The type strain of $S$. espanaensis is strain NRRL 15764 (= LL-C19004-NS29).

Saccharothrix mutabilis comb. nov. Saccharothrix mutabilis (mu. ta' bi. lis. L. adj. mutabilis, changeable, variable, inconstant, referring to the variety of colony morphologies observed, particularly on rich organic media). Substrate mycelium is yellow to yellowish brown. White aerial mycelium is produced on most media. With exposure to 
light, the aerial mycelium may turn orangish yellow. Light yellow to yellowish brown soluble pigments are produced on some media, such as Czapek sucrose agar or glucose-yeast extract agar. Casein, esculin, hippurate, hypoxanthine, starch, and tyrosine are hydrolyzed or decomposed, but adenine, allantoin, guanine, urea, and xanthine are not. Nitrate is reduced to nitrite. Phosphatase is produced. Acetate, citrate, DL-lactate, DL-malate, propionate, and succinate are assimilated; benzoate, mucate, oxalate, and DLtartrate are not assimilated. Acid is produced from L-arabinose, cellobiose, dextrin, D-fructose, D-galactose, Dglucose, glycerol, myo-inositol, lactose, D-mannose, melibiose, $\alpha$-methyl-D-glucoside, raffinose, salicin, sucrose, trehalose, and D-xylose; no acid is produced from adonitol, dulcitol, meso-erythritol, L-rhamnose, and D-sorbitol. Growth occurs in the presence of $3 \% \mathrm{NaCl}$ but not in the presence of $4 \% \mathrm{NaCl}$. The temperature range for growth is 15 to $45^{\circ} \mathrm{C}$. The guanine-plus-cytosine content of the DNA is $73.1 \mathrm{~mol} \%$ (thermal denaturation midpoint method). Isolated from soil. Produces the antibiotic polynitoxin. The type strain of $S$. mutabilis is strain NRRL B-16077 (= ATCC $31520=$ SKF-AAA025).

A strain previously described (17) as "N. mutabilis subsp. cryophilis" also can now be included in the genus Saccharothrix based on morphological and chemotaxonomic data. A comparison of the physiological properties of this organism with those of the other Saccharothrix species, as well as the lack of species level DNA relatedness $(>70 \%)$ to any of the other species (including $S$. mutabilis), indicated that this strain represents a new species, Saccharothrix cryophilis, which is formally described below.

Saccharothrix cryophilis sp. nov. Saccharothrix cryophilis (cry. o. phil' is. L. adj. cryophilis, cold loving, referring to the low permissive temperature range for growth). Pale yellow substrate mycelium is produced on most media. White to yellowish white aerial mycelium is produced, particularly on inorganic salts-starch agar or glycerol-asparagine agar. No soluble pigments are produced. Esculin, tyrosine, and urea are hydrolyzed or decomposed, but adenine, allantoin, casein, hippurate, hypoxanthine, starch, and xanthine are not. Nitrate is reduced to nitrite. Phosphatase is produced. Acetate, DL-lactate, DL-malate, oxalate, propionate, and succinate are assimilated; benzoate, citrate, mucate, and DL-tartrate are not assimilated. Acid is produced from D-fructose, D-galactose, D-glucose, glycerol, myo-inositol, lactose, maltose, D-mannose, and trehalose; no acid is produced from adonitol, L-arabinose, cellobiose, dextrin, dulcitol, meso-erythritol, melibiose, L-rhamnose, salicin, D-sorbitol, sucrose, D-xylose, $\alpha$-methyl-D-glucoside, and $\beta$-methyl-D-xyloside; and acid production from glycerol and raffinose is variable. Growth occurs in the presence of $4 \% \mathrm{NaCl}$ but not in the presence of $5 \% \mathrm{NaCl}$. The temperature range for growth is 10 to $33^{\circ} \mathrm{C}$. The guanine-pluscytosine content of the DNA is $71.4 \mathrm{~mol} \%$ (thermal denaturation midpoint method). Isolated from soil. Produces the antibiotic dopsisamine. The type strain of $S$. cryophilis is strain NRRL B-16238 (= IFO $14475=$ Y. Okami TS-1980).

\section{ACKNOWLEDGMENTS}

Appreciation is expressed to E. N. Hoekstra for assistance in the evaluation of physiological properties, chemotaxonomy, and DNA purification and to A. J. Lyons for determinations of DNA relatedness.

\section{LITERATURE CITED}

1. Cote, R., P.-M. Daggett, M. J. Gantt, R. Hay, S.-C. Hay, and P. Pienta. 1984. ATCC media handbook, 1st ed. American Type Culture Collection, Rockville, Md.

2. Gordon, R. A., D. A. Barnett, J. E. Handerhan, and C. H. Pang. 1974. Nocardia coeliaca, Nocardia autotrophica, and the nocardin strain. Int. J. Syst. Bacteriol. 24:54-63.

3. Kurtzman, C. P., M. J. Smiley, C. J. Johnson, L. J. Wickerham, and G. B. Fuson. 1980. Two new and closely related heterothallic species, Pichia amylophila and Pichia mississippiensis: characterization by hybridization and deoxyribonucleic acid reassociation. Int. J. Syst. Bacteriol. 30:208-216.

4. Kurup, P. V., and J. A. Schmitt. 1973. Numerical taxonomy of Nocardia. Can. J. Microbiol. 19:1035-1048.

5. Labeda, D. P. 1986. Transfer of "Nocardia aerocolonigenes" (Shinobu and Kawato 1960) Pridham 1970 into the genus Saccharothrix Labeda, Testa, Lechevalier, and Lechevalier 1984 as Saccharothrix aerocolonigenes sp. nov. Int. J. Syst. Bacteriol. 36:109-110.

6. Labeda, D. P. 1988. An evaluation of strains of the genus Saccharothrix by numerical taxonomic and molecular taxonomic methods, p. 227-232. In Y. Okami, T. Beppu, and H. Ogawara (ed.), Biology of actinomycetes '88. Japan Scientific Society Press, Tokyo.

7. Labeda, D. P., and A. J. Lyons. 1989. Saccharothrix texasensis sp. nov. and Saccharothrix waywayandensis sp. nov. Int. J. Syst. Bacteriol. 39:355-358.

8. Labeda, D. P., R. T. Testa, M. P. Lechevalier, and H. A. Lechevalier. 1984. Saccharothrix: a new genus of the Actinomycetales related to Nocardiopsis. Int. J. Syst. Bacteriol. 34:426-431.

9. Lechevalier, M. P., C. DeBievre, and H. A. Lechevalier. 1977. Chemotaxonomy of aerobic actinomycetes: phospholipid composition. Biochem. Syst. Ecol. 5:249-260.

10. Lechevalier, M. P., and H. A. Lechevalier. 1980. The chemotaxonomy of actinomycetes, p. 227-291. In A. Dietz and D. W. Thayer (ed.), Actinomycete taxonomy. Special publication no. 6. Society for Industrial Microbiology, Arlington, Va.

11. Marmur, J. 1961. A procedure for the isolation of deoxyribonucleic acid from microorganisms. J. Mol. Biol. 3:208-218.

12. Marmur, J., and P. Doty. 1962. Determination of the base composition of deoxyribonucleic acid from its thermal denaturation temperature. J. Mol. Biol. 5:109-118.

13. Seidler, R. J., M. D. Knittel, and C. Brown. 1975. Potential pathogens in the environment: cultural reactions and nucleic acid studies on Klebsiella pneumoniae from chemical and environmental sources. Appl. Microbiol. 29:819-825.

14. Seidler, R. J., and M. Mandel. 1971. Quantitative aspects of deoxyribonucleic acid renaturation: base composition, state of chromosome replication, and polynucleotide homologies. J. Bacteriol. 106:608-614.

15. Shearer, M. C., P. M. Colman, and C. H. Nash III. 1983. Nocardiopsis mutabilis, a new species of nocardioform bacteria isolated from soil. Int. J. Syst. Bacteriol. 33:369-374.

16. Shirling, E. B., and D. Gottlieb. 1966. Methods for characterization of Streptomyces species. Int. J. Syst. Bacteriol. 16: 313-340.

17. Takahashi, A., K. Hotta, N. Saito, M. Morioka, Y. Okami, and H. Umezawa. 1986. Production of novel antibiotic, dopsisamine, by a new subspecies of Nocardiopsis mutabilis with multiple antibiotic resistance. J. Antibiot. 39:175-183. 